\title{
HRTEM and EELS Analysis of Interfacial Reactions in Ti/Si $\mathbf{1}_{-\mathrm{x}} \mathbf{G e} \mathrm{x}_{\mathrm{x}} / \mathrm{Si}(100)$
}

\author{
J. Yamasaki*, N. Tanaka*, O. Nakatsuka*, A. Sakai**, S. Zaima***, and Y. Yasuda** \\ *CIRSE, Nagoya University, Nagoya, 464-8603, Japan \\ **Department of Crystalline Materials Science, Nagoya University, Nagoya, 464-8603, Japan \\ ***CCRAST, Nagoya University, Nagoya, 464-8603, Japan
}

With the dimension of electronic devices decreasing, contact resistance at metal/Si interfaces has become one of the most important problems. As one of the solution of this problem, it has been proposed to use $\mathrm{Si}_{1-\mathrm{x}} \mathrm{Ge}_{\mathrm{x}}$ films as intermediate layers between $\mathrm{Si}$ substrates and metal films such as Ti[1]. It is known that under annealing, interfacial reactions between $\mathrm{Si}_{1-\mathrm{x}} \mathrm{Ge}_{\mathrm{x}}$ and $\mathrm{Ti}$ layers lead to a production of $\mathrm{C} 49-\mathrm{Ti}\left(\mathrm{Si}_{1-\mathrm{x}} \mathrm{Ge}_{\mathrm{x}}\right)_{2}$ and finally to a transformation into $\mathrm{C} 54-\mathrm{Ti}\left(\mathrm{Si}_{1-\mathrm{x}} \mathrm{Ge}_{\mathrm{x}}\right)_{2}$ which is a low resistivity phase. For more detailed understanding and well-defined controlling of the interfacial reactions, it is necessary to investigate the phenomena in an atomistic level. In the present study, we clarified the nano-structures produced by the interfacial reactions in $\mathrm{Ti} / \mathrm{Si}_{1-\mathrm{x}} \mathrm{Ge}_{\mathrm{x}} / \mathrm{Si}(100)$ system by means of high resolution TEM (HRTEM) and electron energy loss spectroscopy (EELS).

$\mathrm{Si}_{1-\mathrm{x}} \mathrm{Ge}_{\mathrm{x}}$ layers were epitaxially grown on $\mathrm{Si}(100)$ substrates by chemical vapor deposition. We prepared two types of $\mathrm{Si}_{1-\mathrm{x}} \mathrm{Ge}_{\mathrm{x}}$ layers with different Ge fractions, that is, $\mathrm{x}=0.14$ and 0.46 . Then Ti films with a thickness of $30 \mathrm{~nm}$ were deposited on the $\mathrm{Si}_{1-\mathrm{x}} \mathrm{Ge}_{\mathrm{x}}$ layers by electron-beam evaporation. The interfacial reactions of $\mathrm{Ti} / \mathrm{Si}_{1-x} \mathrm{Ge}_{\mathrm{x}}$ were promoted by annealing at $550{ }^{\circ} \mathrm{C}$ for 10 minutes and following rapid thermal annealing (RTA) at $750{ }^{\circ} \mathrm{C}$ for 30 seconds, the same as in practical device processes. The cross-sectional specimens of the $\mathrm{Ti} / \mathrm{Si}_{1-\mathrm{x}} \mathrm{Ge} \mathrm{x}_{\mathrm{x}} / \mathrm{Si}(100)$ hetero-structures were prepared by ion-milling method with $3 \mathrm{kV} \mathrm{Ar}^{+}$ion. HRTEM observations and EELS measurements of the specimens were performed using a $200 \mathrm{kV}$ TEM (JEM-2010F) equipped with an EELS spectrometer (Gatan DigiPEELS 766). EELS spectra from local areas 5-25 $\mathrm{nm}$ in diameter were obtained by using of a spectrometer-entrance aperture with TEM operated in the imaging mode.

In Fig.1(a), we show the cross-sectional TEM image of $\mathrm{Ti} / \mathrm{Si}_{0.54} \mathrm{Ge}_{0.46} / \mathrm{Si}(100)$ after $550{ }^{\circ} \mathrm{C}$ annealing. Under the poly-crystalline layer with a thickness of about $30 \mathrm{~nm}$, the islands about $100 \mathrm{~nm}$ in size are formed at intervals and it is suggested that the islands trigger discontinuous C54 films after following $750^{\circ} \mathrm{C}$ RTA[2,3]. From the HRTEM observation shown in Fig.1(b), we clarified that their structure is $\mathrm{Ti}_{6} \mathrm{Ge}_{5}$-type. Moreover, from appearance of the Si core-loss edge in EELS spectrum obtained by one of them (Fig.2(a)), it is concluded that the islands contain $\mathrm{Si}$ atoms, namely, are $\mathrm{Ti}_{6}\left(\mathrm{Si}_{1-\mathrm{x}} \mathrm{Ge}_{\mathrm{x}}\right)_{5}$. Although the shape of the $\mathrm{Si}$ core-loss edge is sensitive to bonding condition of Si atoms, those from the surface layer and the islands are very similar in Fig.2. The result means that the surface poly-crystalline layer is also $\operatorname{Ti}_{6}\left(\mathrm{Si}_{1-\mathrm{x}} \mathrm{Ge}_{\mathrm{x}}\right)_{5}$. From the results, we can obtain the following reaction model. Firstly, Si and Ge atoms may diffuse into the deposited Ti layer from the $\mathrm{Si}_{1-\mathrm{x}} \mathrm{Ge}_{\mathrm{x}}$ layer and the $\mathrm{Ti}_{6}\left(\mathrm{Si}_{1-\mathrm{x}} \mathrm{Ge}_{\mathrm{x}}\right)_{5}$ layer may be produced. Then Ti atoms may diffuse into less strained parts of the $\mathrm{Si}_{1-\mathrm{x}} \mathrm{Ge}_{\mathrm{x}}$ layer and form the $\mathrm{Ti}_{6}\left(\mathrm{Si}_{1-\mathrm{x}} \mathrm{Ge}_{\mathrm{x}}\right)_{5}$ islands, since the $\mathrm{Si}_{1-\mathrm{x}} \mathrm{Ge}_{\mathrm{x}}$ layer contains compressive strains periodically induced by lattice misfit between the substrate $\mathrm{Si}(100)$ and the $\mathrm{Si}_{1-\mathrm{x}} \mathrm{Ge}_{\mathrm{x}}$ layer.

In contrast to higher Ge fraction samples in which C54 islands are observed, C54 layer with a thickness of about $50 \mathrm{~nm}$ is formed in lower Ge fraction samples $(\mathrm{x}=0.14)$ after following $750^{\circ} \mathrm{C}$ RTA(Fig.1(c)). Since the Ge fraction is smaller and therefore strains are also smaller, Ti atoms may diffuse into the $\mathrm{Si}_{1-\mathrm{x}} \mathrm{Ge}_{\mathrm{x}}$ layer not locally but uniformly in this case. It is also found that two poly-crystalline layers about 5-10nm in thickness exist over the C54 layer shown as 
the arrows in the figure and they never be detected by X-ray diffraction. In Figs.2(b) and (c), we show EELS spectra from these layers and a $\mathrm{C} 49$ layer in $\mathrm{x}=0.14$ sample after $550^{\circ} \mathrm{C}$ annealing for a reference. By detailed comparison among them, it is found that the lower poly-crystalline layer is $\mathrm{C} 49-\mathrm{Ti}\left(\mathrm{Si}_{1-\mathrm{x}} \mathrm{Ge}_{\mathrm{x}}\right)_{2}$ and that the upper layer is $\mathrm{Ti}_{6}\left(\mathrm{Si}_{1-\mathrm{x}} \mathrm{Ge}_{\mathrm{x}}\right)_{5}$ the same as the islands mentioned above. These layers may have failed to transform into the C54 phase by some surface effects. Since both $\mathrm{C} 49-\mathrm{Ti}\left(\mathrm{Si}_{1-\mathrm{x}} \mathrm{Ge}_{\mathrm{x}}\right)_{2}$ and $\mathrm{Ti}_{6}\left(\mathrm{Si}_{1-\mathrm{x}} \mathrm{Ge}_{\mathrm{x}}\right)_{5}$ are high resistivity phases, they are undesirable for contact devices.

In the present study, we analyzed the nano-structures in the annealed $\mathrm{Ti} / \mathrm{Si}_{1-\mathrm{x}} \mathrm{Ge}_{\mathrm{x}} / \mathrm{Si}$ systems and succeeded in clarifying their existence and structures by HRTEM and EELS. From the results, atomic diffusion and reaction processes in the interfacial reactions were discussed. It is considered that applications of this type of detailed analysis to various kinds of advanced materials lead to improvements in device technology.

\section{References}

[1] S. Zaima and Y. Yasuda, J. Vac. Sci. Technol. B 16 (1998) 2623.

[2] A.Tobioka et al., Materials Science and Engineering B89 (2002) 373.

[3] J. Yamasaki et al., Proc. 15 ${ }^{\text {th }}$ Int. Conf. Electron Microsc., (2002) 43.

[4] This research was partly supported by Grant-in-aid for scientific research priority areas (A) from Ministry of Education, Science, Sport, Culture and Technology, named as "Functionized Global Interface Integration (\#409)".
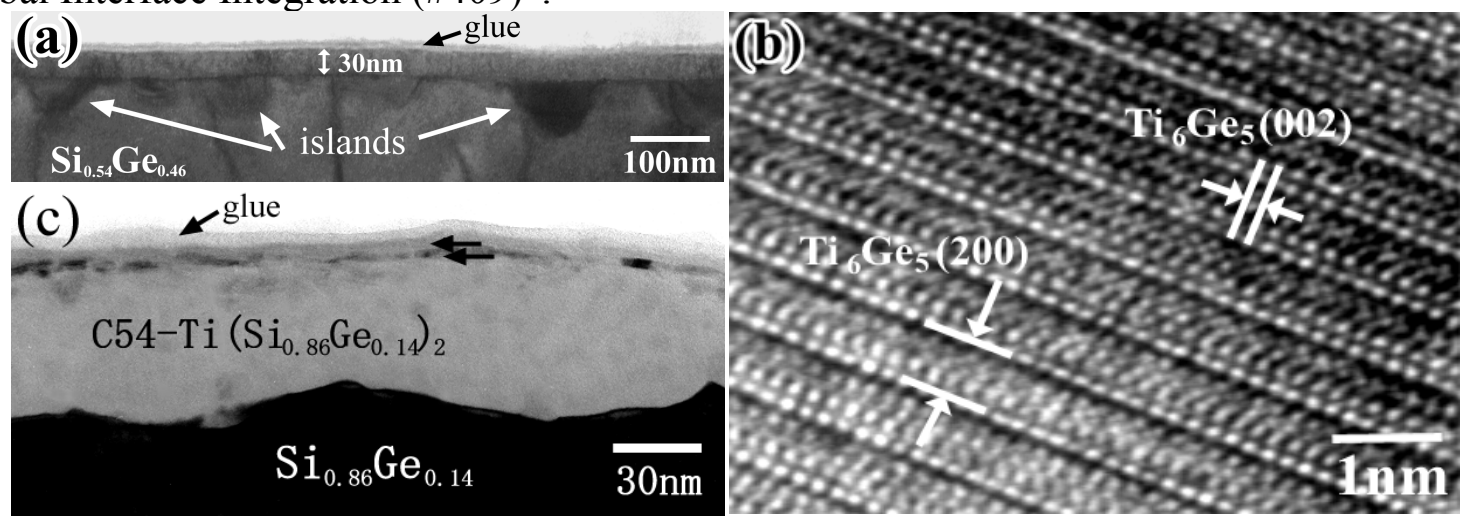

FIG.1. Cross-sectional TEM images of (a) higher $(x=0.46)$ and (c) lower $(x=0.14)$ Ge fraction samples. (b) HRTEM image of an island such as shown in (a).
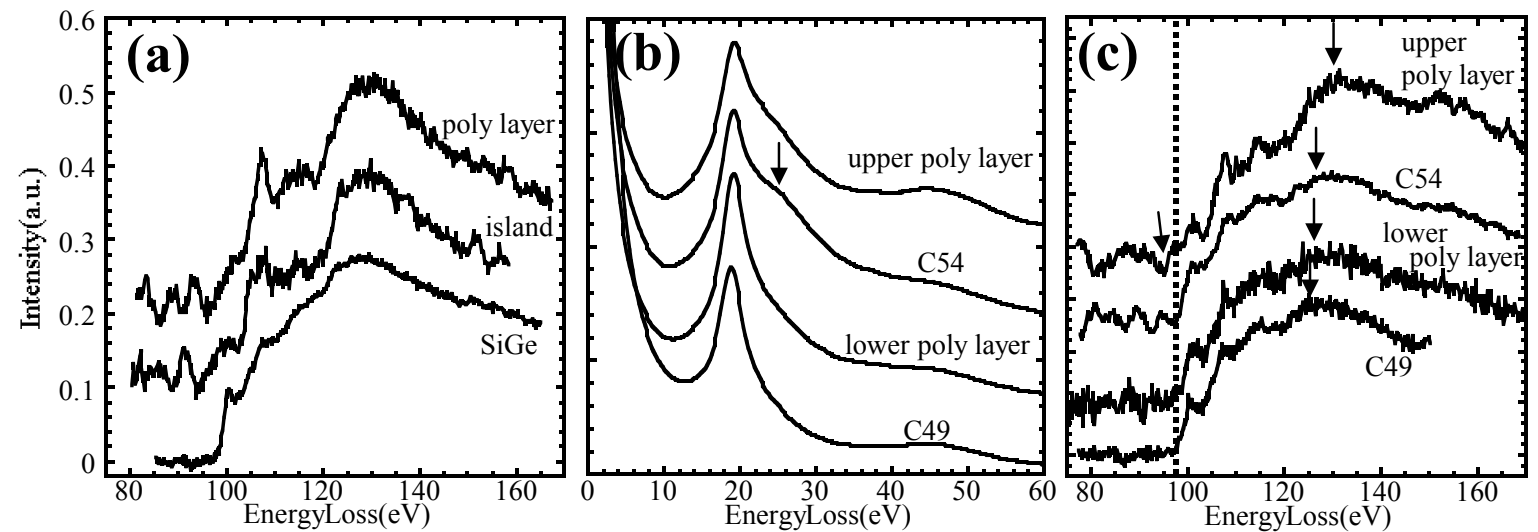

FIG.2. EELS spectra from samples in which Ge fraction (a) $x=0.46$ and (b)(c) $x=0.14$. By detailed comparison, it is found that lower poly layer in (c) is $\mathrm{C} 49-\mathrm{Ti}\left(\mathrm{Si}_{1-\mathrm{x}} \mathrm{Ge}_{\mathrm{x}}\right)_{2}$ and that upper poly layer in (c), poly layer and island in (a) are the same, namely, $\operatorname{Ti}_{6}\left(\mathrm{Si}_{1-\mathrm{x}} \mathrm{Ge}_{\mathrm{x}}\right)_{5}$. 